University of Nebraska - Lincoln

DigitalCommons@University of Nebraska - Lincoln

\title{
Proportion of the Litter Farrowed, Litter Size, and Progesterone and Estradiol Effects on Piglet Birth Intervals and Stillbirths
}

J. L. Vallet

USDA-ARS, Jeff.Vallet@ars.usda.gov

J. R. Miles

USDA-ARS, jeremy.miles@usda.gov

T. M. Brown-Brandl

USDA-ARS, Tami.BrownBrandl@ARS.USDA.GOV

J. A. Nienaber

USDA-ARS

Follow this and additional works at: https://digitalcommons.unl.edu/hruskareports

Vallet, J. L.; Miles, J. R.; Brown-Brandl, T. M.; and Nienaber, J. A., "Proportion of the Litter Farrowed, Litter Size, and Progesterone and Estradiol Effects on Piglet Birth Intervals and Stillbirths" (2010). Roman L. Hruska U.S. Meat Animal Research Center. 255.

https://digitalcommons.unl.edu/hruskareports/255

This Article is brought to you for free and open access by the U.S. Department of Agriculture: Agricultural Research Service, Lincoln, Nebraska at DigitalCommons@University of Nebraska - Lincoln. It has been accepted for inclusion in Roman L. Hruska U.S. Meat Animal Research Center by an authorized administrator of DigitalCommons@University of Nebraska - Lincoln. 


\title{
Proportion of the litter farrowed, litter size, and progesterone and estradiol effects on piglet birth intervals and stillbirths ${ }^{\text {is }}$
}

\author{
J.L. Vallet*, J.R. Miles, T.M. Brown-Brandl, J.A. Nienaber \\ USDA, ARS, Roman L. Hruska U.S. Meat Animal Research Center, Clay Center, NE 68933, United States
}

\section{A R T I C L E I N F O}

\section{Article history:}

Received 6 February 2009

Received in revised form 3 November 2009

Accepted 11 November 2009

Available online 18 November 2009

\section{Keywords:}

Stillbirth

Progesterone

Estradiol

Farrowing

Birth interval

Swine

\begin{abstract}
A B S T R A C T
Stillbirth in swine ranges from 2 to $9 \%$, resulting in a significant loss of piglets. Previous studies clearly indicate a relationship between prolonged birth intervals and stillbirth, but factors influencing birth intervals are not fully known. To characterize birth intervals and stillbirth, farrowing was recorded during three farrowing seasons. Blood samples were collected on d 110 and d 113 of gestation, and were assayed for progesterone and estrogen. Relationships between estrumate (cloprostenol sodium, an analogue of prostaglandin $\mathrm{F}_{2 \alpha}$ ) usage, litter size, proportion of the litter farrowed, progesterone and estrogen concentrations, birth intervals, and stillbirth were analyzed using regression analysis. A clear relationship between birth intervals and stillbirth was observed. Stillbirth rate was unaffected by birth intervals of $<1 \mathrm{~h}$, and increased $(P<0.01)$ for birth intervals $>1 \mathrm{~h}$. A significant negative association between litter size and birth intervals was observed $(P<0.01)$. Birth intervals were unaffected by proportion of the litter farrowed until the last piglet in the litter, whose birth interval increased dramatically $(1.5$-fold; $P<0.01)$. Stillbirth rates increased as proportion of the litter farrowed increased, and a dramatic increase in stillbirth occurred for the last piglet in the litter. Neither $\mathrm{d} 110$ nor 113 plasma progesterone concentrations were associated with litter size, birth intervals, or stillbirth rates. Curvilinear relationships were present between d 110 or 113 plasma estradiol concentrations and litter size. However, neither d 110 nor 113 estradiol concentrations were associated with birth intervals or stillbirth rates. These results indicate that (1) birth intervals greater than $1 \mathrm{~h}$ are associated with increased stillbirth; (2) larger litter size reduces birth intervals; (3) the last piglet in the litter has both a prolonged birth interval and increased risk of stillbirth; (4) plasma progesterone before farrowing does not influence birth intervals or stillbirth; and (5) plasma estradiol does not influence birth interval or stillbirth, despite a positive relationship between litter size and plasma estradiol. An understanding of the effects of litter size and proportion of the litter farrowed on birth intervals might be exploited to decrease stillbirth in piglets.
\end{abstract}

Published by Elsevier B.V.

\footnotetext{
is Mention of trade names or commercial products in this article is solely for the purpose of providing specific information and does not imply recommendation or endorsement by the U.S. Department of Agriculture.

* Corresponding author. Tel.: +1 402762 4187; fax: +1 4027624382.

E-mail address: Jeff.Vallet@ars.usda.gov (J.L. Vallet).
}

\section{Introduction}

The incidence of stillbirth of piglets ranges from 2 to 9\% and represents a significant loss to swine producers (Fahmy and Bernard, 1971; Fahmy et al., 1978; Cassady et al., 2001; van Rens and van der Lende, 2004; Mesa et al., 2006; Oliviero et al., 2008). Numerous studies have examined factors influencing stillbirth rate. Two primary factors associated with increased stillbirth rate appear to be pro- 
longed birth intervals (Sprecher et al., 1974; van Dijk et al., 2005) and low birth weights (Fahmy and Bernard, 1971; Mesa et al., 2006). One approach to reducing the incidence of stillbirth in pigs is to decrease birth intervals, but little is known of the endogenous factors controlling birth intervals in pigs.

Farrowing is initiated by a decline in progesterone (Dziuk, 1975; Guthrie, 1985). Along with declining progesterone, placental estrogen production rises as farrowing approaches. The amount of estrogen is correlated with litter size (Edgerton et al., 1971; Kensinger et al., 1986) and placental estrogen production could explain the previously described decrease in average birth interval as litter size increases (Guthrie, 1985; Eldridge-White et al., 1989). We hypothesized that differences in pre-farrowing progesterone or estrogen influence birth intervals and therefore contribute to the incidence of stillbirth. The objectives of the current experiment were to assess interrelationships between litter size, proportion of the litter farrowed, pre-farrowing plasma progesterone and estradiol concentrations, birth intervals, and stillbirth rate to gain insight into factors that might be manipulated to decrease birth intervals and the incidence of stillbirth.

\section{Materials and methods}

All animal procedures were approved by the USMARC institutional animal care and use committee. First-parity gilts from the USMARC BX swine population (crossbred population composed of York, maternal Landrace, paternal Landrace and Duroc breeds) were mated at estrus (Day 0 ) using artificial insemination. Normal husbandry procedures were used during gestation, and sows were moved to the farrowing facility at about $110 \mathrm{~d}$ of gestation. Single $10 \mathrm{~mL}$ blood samples were collected from the jugular vein of each gilt on d 110 and d 113 of gestation into tubes containing $1 \mathrm{~mL} 3.8 \%$ sodium citrate. Blood samples were centrifuged ( $1000 \times \mathrm{g}$ for $10 \mathrm{~min})$ to recover plasma, and plasma was frozen at $-20^{\circ} \mathrm{C}$ until assayed for progesterone and estradiol by radioimmunoassay. Data for this experiment were collected in 2006 during the May (68 gilts), July (59 gilts) and November (34 gilts) farrowing seasons at USMARC. The number of gilts farrowing in each season was approximately 100 within a 21 -d period except for the November season, which was a mixture of gilts and second-parity sows (second-parity sows were excluded from the analysis). Normal husbandry was used in the farrowing house, including the use of estrumate (cloprostenol sodium, an analogue of prostaglandin [PG] $\mathrm{F}_{2 \alpha}$; Intervet Inc., Millsboro, $\mathrm{DE}$ ) to induce farrowing in gilts that had not farrowed by $116 \mathrm{~d}$ of gestation ( 83 gilts received estrumate versus 78 that did not). Farrowing was attended by swine unit personnel during an 8-h period each day, and assistance was provided to gilts when birth intervals were prolonged or the farrowing process had ceased to progress. Data for piglets born either with assistance or after a previous piglet had received assistance (three gilts in the 03 season, 14 gilts in the 04 season and 0 gilts in the 06 season) were excluded from the analysis.

\subsection{Video monitoring of the birth process}

Nine video cameras (Panasonic WV-BP310, Panasonic Corp., Secaucus, NJ) equipped with wide-angle lenses (WVLA210C3) were each mounted at the back of a gestation crate. Output from each camera was input into a Panasonic WJ-FS 416 16-camera multiplexer whose output was then recorded using a Panasonic AG-6040 time lapse video cassette recorder (VCR). The VCR was set to record for a 24-h period on a single 120 -min tape; using this equipment, an image was captured from each camera at 1 - to 3-s intervals. Pigs were arranged in farrowing crates in order of expected farrowing dates; as pigs completed farrowing, cameras were moved to the next gilt that had not farrowed. Cameras were moved once a day. Using this equipment approximately two-thirds of the gilts farrowing were recorded. Individual piglet birth intervals were recovered retrospectively from the tapes by monitoring the recordings of each camera played back at greater speed, with reduction to normal playback speed if necessary. The time (hour and minute) of the birth of each piglet was recorded as well as whether the piglet was born alive, stillborn (stillborn piglets displayed no movement), or mummified (piglets displaying no movement with clear signs of decay [swelling, abnormal appearance]). The birth interval of the first piglet in the litter was set to a missing value and subsequent piglet birth intervals were recorded as the time from the birth of the previous piglet. The number of piglets (live, stillborn, and mummies) in each litter was also recorded by farm staff on the morning after farrowing; this was used to assist in the distinction between stillborn piglets and mummies for every litter. Mummies were excluded from the analysis.

\subsection{Progesterone and estradiol radioimmunoassays}

Plasma progesterone was measured retrospectively using a Coat-a-Count progesterone radioimmunoassay kit (Seimans Medical Solutions Diagnostics, Los Angeles, CA) using the procedure included with the kit. To validate the assay, barrow plasma was spiked with known amounts of progesterone and assayed. The slope of the relationship between measured and added progesterone was 1.07. Inter- and intra-assay coefficients of variation for the assays were $5.5 \%$ and $2.6 \%$, respectively. A previously validated estradiol radioimmunoassay was used for the retrospective analysis of plasma estradiol (Redmer and Day, 1981; Christenson et al., 1985). The inter- and intra-assay coefficients of variation for this assay were $22 \%$ and $1.5 \%$.

\subsection{Statistical analysis}

To examine changes in plasma progesterone and estrogen pre-farrowing, samples collected on d 110 and d 113 were converted to days pre-farrowing by subtracting either 110 or 113 , respectively, from the actual gestation length. PROC MIXED (Statistical Analysis System version 9.1, SAS Institute, Cary, NC) was then used to characterize relationships between number of days pre-farrowing and plasma steroid concentrations. The model used included effects of season and the linear, quadratic, and cubic effects of days 
pre-farrowing as fixed effects and gilt-within-season as a random effect.

PROC GLIMMIX was used to analyze the incidence of stillbirth for the effects of birth interval, birth interval of the previous piglet, and birth interval of the second previous piglet, to determine possible carryover effects of birth intervals on subsequent piglets. Season was included in each model as a fixed effect and gilt-within-season was included as a random effect. In a separate analysis, birth intervals were combined into five categories according to the following scheme: 0-40-min intervals were classified as $20 \mathrm{~min}, 40-80-\mathrm{min}$ intervals were classified as $60 \mathrm{~min}$, 80-120-min intervals were classified as $100 \mathrm{~min}, 120-160$ min intervals were classified as $140 \mathrm{~min}$, and intervals greater than $160 \mathrm{~min}$ were classified as $180 \mathrm{~min}$. PROC GLIMMIX was used to generate least squares means for stillbirth rate for each birth interval category. The model included effect-of-season as a fixed effect and gilt-withinseason as a random effect. Orthogonal contrasts were used to delineate differences between means. Contrasts used compared $20 \mathrm{~min}$ with $60 \mathrm{~min}, 140 \mathrm{~min}$ with $180 \mathrm{~min}$, $100 \mathrm{~min}$ with the average of 140 and $180 \mathrm{~min}$, and the average of 20 and $60 \mathrm{~min}$ categories compared to the average of 100,140 and 180 min categories.

PROC MIXED was used to analyze individual piglet birth interval data for effects of farrowing season, use of estrumate, litter size, their interactions, proportion of the litter farrowed, and d 110 and d 113 plasma progesterone and estradiol concentrations. Individual piglet birth intervals were log transformed to equalize variances. Birth orders were partially confounded with litter size because small litter sizes were not represented in the greater birth orders. To solve this problem, birth orders were converted to the proportion of the litter farrowed by dividing the piglet number in the birth order by the litter size for that litter. This resulted in a pseudo-continuous distribution of proportion farrowed across all litters. These data were subsequently grouped into categories using the following scheme: $0-0.15$ piglets were assigned a value of 0.1 , $0.15-0.25$ piglets were assigned a value of 0.2 and so on until the last category of $0.95-1$, which was assigned a value of 1 . This resulted in 10 proportion farrowed categories with the 1 category containing all piglets that were last in the birth order for their respective litter (because litter size was less than 20 for all litters). Gilt within farrowing season $\times$ use of estrumate $\times$ litter size was included as a random effect in the above model. Orthogonal contrasts were used to further explore changes in birth intervals with increasing proportion of the litter farrowed. Contrasts used were .1 versus .2 ; the average of .1 and .2 versus .3 ; the average of $.1, .2$ and .3 versus .4 ; the average of $.1, .2, .3$ and .4 versus .5 ; the average of $.1, .2, .3, .4$ and .5 versus .6 ; the average of $.1, .2, .3, .4, .5$ and .6 versus .7 ; the average of $.1, .2, .3, .4, .5, .6$ and .7 versus .8 ; the average of $.1, .2, .3, .4, .5, .6, .7$ and .8 versus .9 ; the average of $.1, .2, .3, .4, .5, .6, .7, .8$ and .9 versus 1 . PROC GLIMMIX was used with a similar model to analyze individual stillbirth incidence data for effects of farrowing season, use of estrumate, litter size, their interactions, proportion of the litter farrowed, and d 110 and d 113 plasma progesterone and estradiol concentrations. As for birth interval,

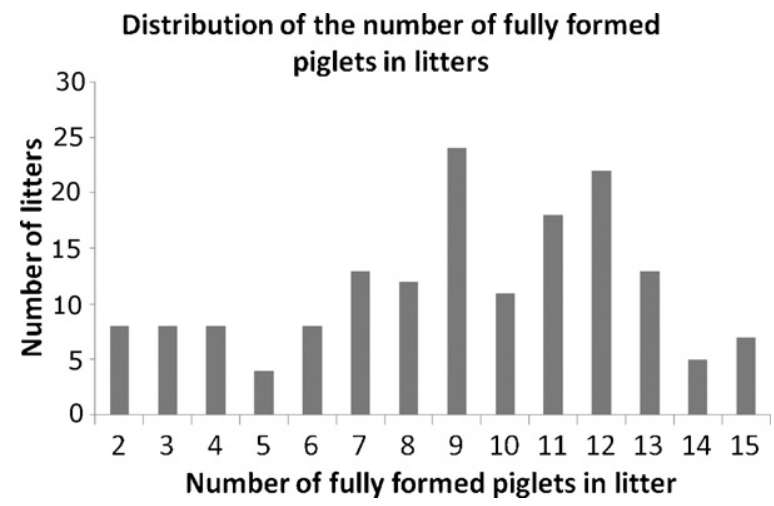

Fig. 1. A histogram of the distribution of the number of fully formed piglets in the 161 litters in this experiment is illustrated.

the same orthogonal contrasts were used to explore the relationship between stillbirth and proportion of the litter farrowed.

PROC MIXED was used to examine the relationships between d 110 and d 113 plasma estradiol concentrations and litter size. Effects of season, estrumate, the linear and quadratic effects of litter size and their interactions were included in the model.

Finally, PROC GLM was used to examine the relationship between the birth interval of the last piglet and the accumulated farrowing time taken to deliver all previous piglets. This was done to determine whether sow fatigue contributes to the prolonged birth interval of the last piglet in each litter. The effects of season, estrumate, litter size and their interactions were included in the model.

\section{Results}

The number of fully formed piglets in the litters for this experiment ranged from 2 to 15 (Fig. 1). Statistical analysis of plasma progesterone and estradiol concentrations indicated significant cubic and linear relationships $(P<0.05)$ respectively, with decreasing days pre-farrowing. Data indicated that plasma progesterone began to decrease $3 \mathrm{~d}$ before farrowing.

PROC GLIMMIX analysis of stillbirth incidence indicated an effect $(P<0.01)$ of piglet birth interval (Fig. 2). Analyses of the effects of birth intervals of the previous piglet and the second previous piglet on stillbirth indicated that these were not significant, thus no carryover effect of birth intervals on the stillbirth rates of subsequent piglets was found. GLIMMIX analysis of birth interval categories indicated that the 20 and 60-min categories were not different, and the 100-, 140-, and 180-min categories were also not different. However, stillbirth rates for the 100-, 140-, and 180 -min categories were greater $(P<0.05)$ than the 20 - and 60-min categories.

PROC MIXED analysis of log transformed individual piglet birth intervals indicated a negative linear effect of litter size $(P<0.01)$, effects of season $(P<0.05)$, and proportion of the litter farrowed $(P<0.01$; Fig. 3$)$. There were no interactions among main effects and no significant effects of estrumate, d 110 or 113 plasma progesterone or estradiol concentrations. Least squares means for birth 


\section{Effect of birth intervals on} stillbirth

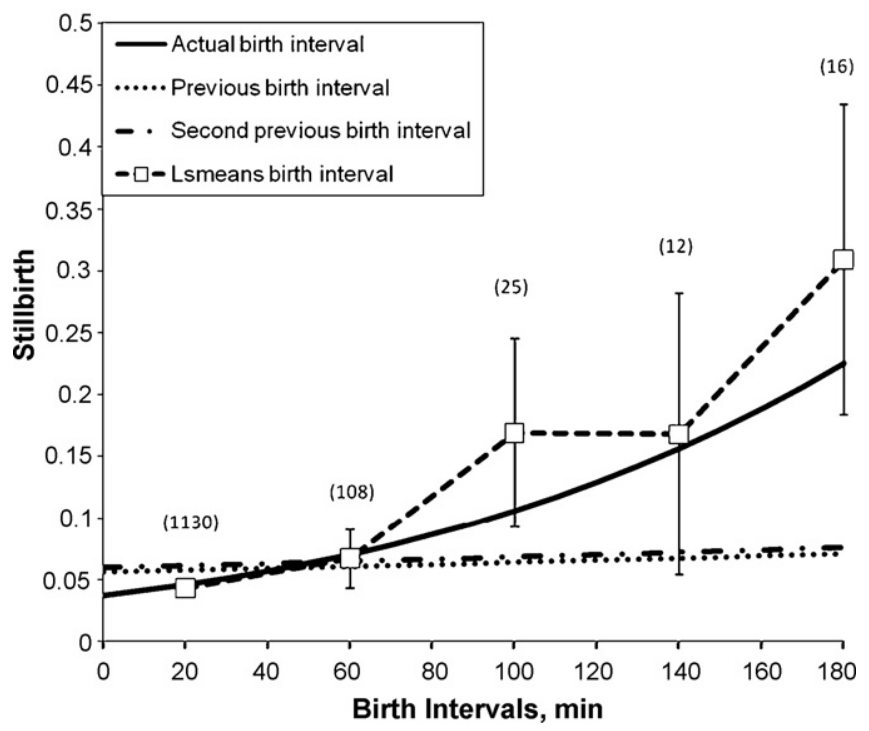

Fig. 2. The graph illustrates the relationship between birth interval of piglets and stillbirth incidence (solid line indicates the prediction line for the relationship between birth interval and stillbirth rate using PROC GLIMMIX and open squares with a broken line indicate the least squares means \pm SEM for stillbirth rate for individual birth interval categories; number of observations for each mean is in parentheses), the relationship between previous piglet birth interval and stillbirth incidence (dotted line), and the relationship between the second previous piglet birth interval and stillbirth incidence (dash-dot line). Only the relationship between the birth interval and stillbirth incidence of piglets was significant $(P<0.05)$. Contrasts indicated that stillbirth incidence was similar for birth intervals of $60 \mathrm{~min}$ or less and for $100 \mathrm{~min}$ or greater, and that incidence of stillbirth for birth interval categories of more than 100 min were greater $(P<0.05)$ than for birth interval categories less than $60 \mathrm{~min}$.
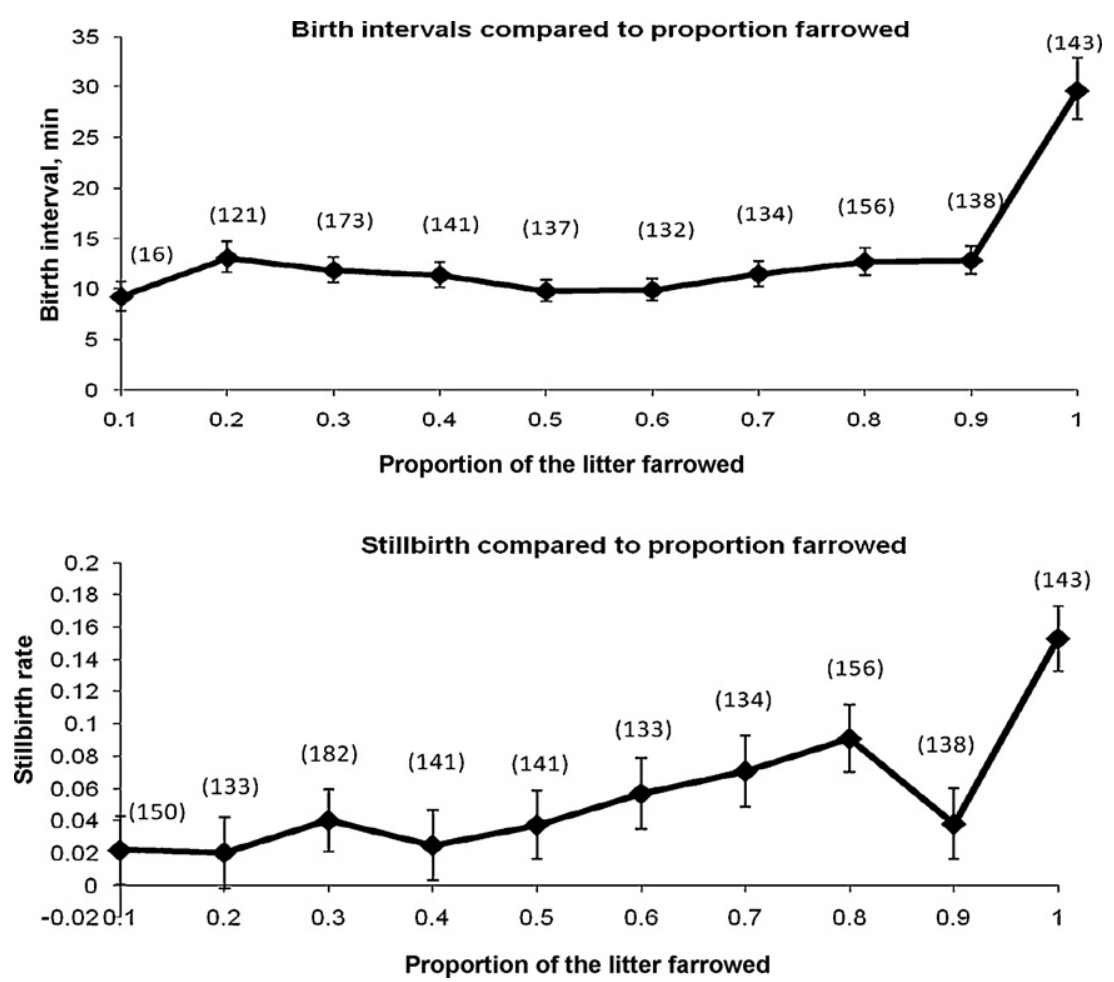

Fig. 3. Least squares means for birth intervals and stillbirth rates for different proportion of the litter farrowed categories are illustrated. The number of observations for each mean is in parentheses. Birth intervals increased $(P<0.05)$ between the 0.1 and 0.2 categories and then were similar for the $0.2-0.9$ categories. A dramatic increase $(P<0.01)$ in birth interval occurred for the last category compared to the average of all previous categories. Stillbirth increased for the $0.7(P<0.05), 0.8(P<0.01)$, and final $(P<0.01)$ proportion farrowed categories compared to all previous categories. 

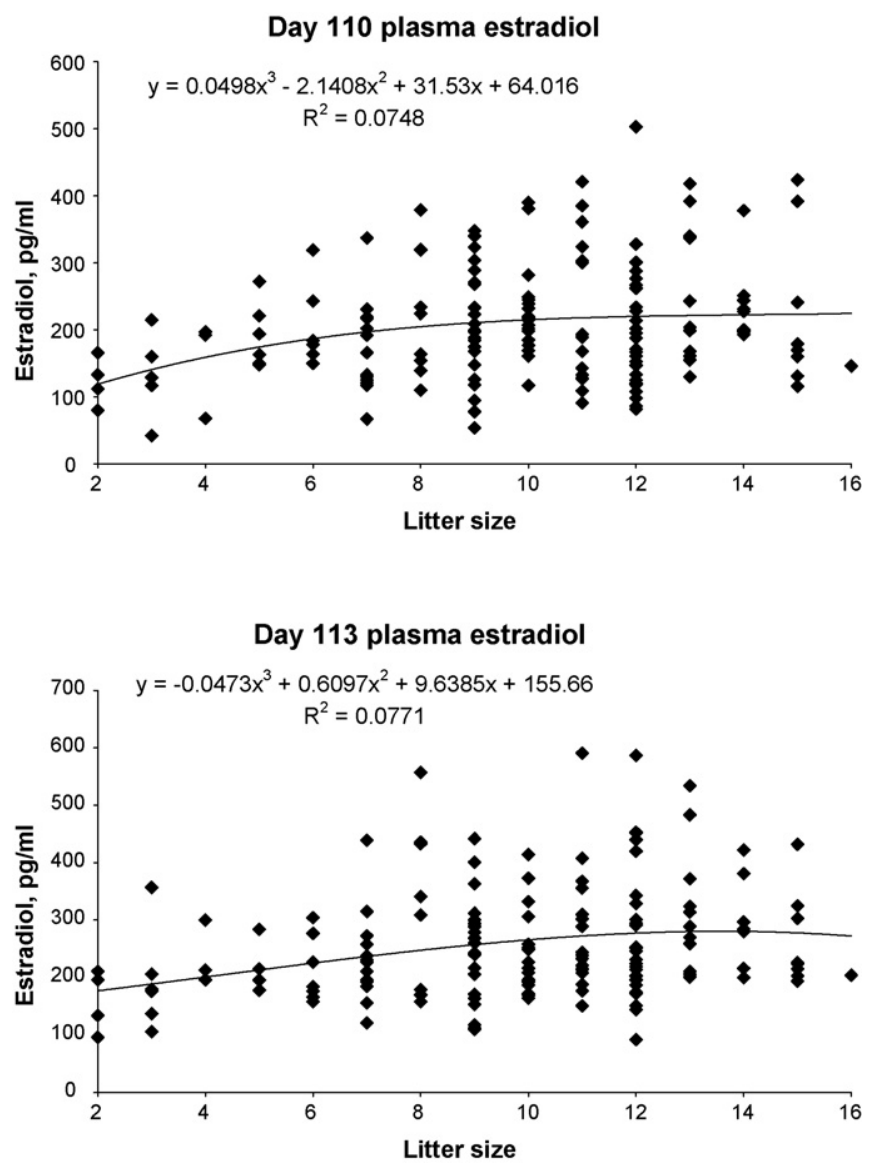

Fig. 4. Scatterplots of $d 110$ and d 113 plasma estradiol concentrations plotted against litter size are illustrated. For both, significant linear $(P \leq 0.01)$ and cubic $(P \leq 0.06)$ effects of litter size on plasma estradiol concentrations were detected.

interval for the November season (16.9 min, range \pm SEM 15.2-18.9; range is provided because log transformation creates a difference in the positive and negative SEM) was greater $(P<0.05)$ than for the May $(12.06$ min, range \pm SEM $11.2-12.99)$ or July (12.4 min, range \pm SEM $11.52-13.41$ ) seasons. Orthogonal contrasts of increasing proportion of the litter farrowed categories indicated an increase $(P<0.05)$ in birth interval between the earliest proportion farrowed category $(0.1)$ and the next category $(0.2)$. Categories 0.2 to 0.9 did not differ. The birth interval of the last piglet farrowed in the litter (category 1.0) was increased $(P<0.01)$ compared to the average of all other piglets in the litter.

PROC GLIMMIX analysis of stillbirth incidence indicated a significant effect of proportion of the litter farrowed (Fig. 3). There were no effects of season, estrumate, litter size, their interactions, or of d 110 and d 113 plasma progesterone or estradiol concentrations on stillbirth incidence. Analysis of contrasts between proportion farrowed categories indicated that stillbirth incidence was greater $(P<0.05,0.01$, and 0.01 , respectively) in the $0.7,0.8$, and 1.0 categories, compared to all previous categories. The greatest incidence of stillbirth was in the 1.0 category.

PROC MIXED analysis of d 110 plasma estradiol concentration indicated positive linear $(P=0.01)$ and cubic
$(P=0.06)$ effects of litter size and effects of season $(P<0.01)$ and use of estrumate (no estrumate $214.9 \pm 9.8 \mathrm{pg} / \mathrm{mL}$ versus estrumate $185.0 \pm 9.4 \mathrm{pg} / \mathrm{mL} ; P<0.05$ ), with no interactions. The $d 110$ plasma estradiol concentrations increased with increasing litter size up to a litter size of eight and then were similar for litter sizes greater than eight (Fig. 4). The d 110 plasma estradiol concentrations from the May $(173.4 \pm 10.2 \mathrm{pg} / \mathrm{mL})$ and November $(184.8 \pm 14.1 \mathrm{pg} / \mathrm{mL})$ seasons did not differ but were less than $(P<0.01)$ the July season $(241.7 \pm 10.4 \mathrm{pg} / \mathrm{mL})$. Analysis of $d 113$ plasma estradiol concentration indicated linear $(P<0.01)$ and cubic $(P=0.01)$ effects of litter size $(P<0.05)$ and effects of season $(P<0.01)$ and estrumate (no estrumate $259.1 \pm 11.5 \mathrm{pg} / \mathrm{mL}$ versus estrumate $224.6 \pm 11.0 \mathrm{pg} / \mathrm{mL} ; P<0.05$ ). Plasma estradiol on $\mathrm{d} 113$ increased with increasing litter size, up to a litter size of 10, and then were relatively constant (Fig. 4). The d 113 plasma estradiol concentrations did not differ between the May $(277.7 \pm 11.9 \mathrm{pg} / \mathrm{mL})$ and July $(254.0 \pm 12.2 \mathrm{pg} / \mathrm{mL})$ seasons and were greater than $(P<0.01)$ the November season $(194.0 \pm 16.6 \mathrm{pg} / \mathrm{mL})$. PROC MIXED analysis indicated that there was no statistically significant relationship between the accumulated time required to deliver all previous piglets and the birth interval of the last piglet. 


\section{Discussion}

Similar to previous reports (Sprecher et al., 1974; van Dijk et al., 2005), prolonged birth intervals are associated with increased incidence of stillbirth, but previous reports indicated that stillbirth incidence is increased for birth intervals greater than 20 min (Dziuk, 1975). In contrast, results from the present study indicated piglets can tolerate birth intervals up to an hour without increased stillbirth rate. In addition, a novel result of the present study was that prolonged birth intervals of earlier piglets did not have significant carryover effects on the incidence of stillbirth in subsequent piglets. Contrary to the hypothesis in the present study, pre-farrowing progesterone and estradiol concentrations were unrelated to birth intervals, despite the fact that estradiol concentrations were associated with litter size. Similar to previous reports (Randall, 1972; van Rens and van der Lende, 2004), the birth interval of the last birth position is specifically prolonged, and is associated with increased stillbirth in this position. Because of the relationship between birth interval and stillbirth, an understanding of the effects of litter size and the last birth position on birth interval may suggest ways to improve the farrowing process, resulting in a decrease in stillbirth.

Previous reports indicated a relationship between prolonged birth intervals and the incidence of stillbirth (Sprecher et al., 1974; van Dijk et al., 2005). Dziuk (1975) reported that stillbirth is likely when individual piglet birth intervals exceed $20 \mathrm{~min}$. However, results from the present study indicated birth intervals of up to an hour did not result in increased incidence of stillbirth. Although this difference may seem minor, it may allow for the possibility of once an hour monitoring of piglet births to rescue piglets that have exceeded the $1 \mathrm{~h}$ threshold. Once an hour monitoring of farrowing with appropriate intervention would seem to be more feasible than monitoring farrowing once every $20 \mathrm{~min}$, especially if an hourly piglet count for each sow could be automated, which seems quite possible with current technology.

Surprisingly, there was a lack of a statistically significant relationship between birth intervals of previous piglets and the stillbirth rates of subsequent piglets. Interpretation of this result must be tempered with the knowledge that piglets that are born consecutively are not necessarily delivered from the same uterine horn (Dziuk and Harmon, 1969). The lack of relationship between birth intervals of previous piglets and incidence of stillbirth in subsequent piglets confirms that the placenta is normally capable of maintaining piglets for longer than the time it takes to farrow the entire litter. This result suggests that if once an hour monitoring was established and an appropriate response to prolonged farrowing was initiated to rescue the piglet, the delivery of the remainder of the litter could be allowed to continue unaided without significant consequences. However, in the present study there was a general increase in the incidence of stillbirth in piglets as farrowing progressed. The greater incidence of stillbirth in piglets born later in the farrowing process suggests that the risk of stillbirth accumulates during the farrowing process. The lack of effect of previous piglet birth intervals on the incidence of stillbirth of subsequent piglets suggests that the increase in stillbirth with increasing proportion of the litter farrowed is not due solely to time, otherwise significant relationships would exist between previous piglet birth intervals and stillbirth of piglets. A possible explanation for this discrepancy could be that the accumulated time does not compromise the piglets in the late stages of the farrowing process; instead, the greater incidence of stillbirth may be due to the accumulation of stress on the placentas or fetal circulation of later-born piglets.

There was no evidence that progesterone concentrations near the end of gestation had any association with birth intervals. Results from the present study also confirmed that large litters are associated with reduced individual piglet birth intervals (Canario et al., 2006). Similar to previous reports (Edgerton et al., 1971; Kensinger et al., 1986), plasma estradiol concentrations on both $d$ 110 and d 113 of gestation increased with increasing litter size. However, simultaneous inclusion of plasma estradiol and litter size in the regression model failed to reduce the significant effect of litter size on birth intervals, and neither d 110 nor 113 plasma estradiol concentrations were associated with birth intervals. A variety of estrogens are secreted by the pig placenta leading up to farrowing, including estrone and estradiol. Estrone is by far the greatest quantity of estrogen secreted (Kensinger et al., 1986), although estradiol is the most potent (Dandliker et al., 1978; Lubahn et al., 1985). Further complicating the issue is the fact that estrogens can be conjugated (both sulfation and glucuronidation; Robertson et al., 1985), which renders them inactive. Endometrial tissues contain estrogen sulfatase enzymes, which restore estrogenic activity to sulfated estrogens (Dwyer and Robertson, 1980). Thus, it is nearly impossible to get a true measure of "active" estrogen at the level of the uterus. Clearly, results from the present study indicate plasma estradiol concentrations are not useful in predicting birth intervals. From the present results, the concept that increasing placental estrogen secretion before farrowing contributes to preparation of the uterus for farrowing seems unlikely; however, we cannot conclude that estrogen does not effect farrowing intervals due to the difficulties associated with measuring "active" estrogen at the level of the uterus.

Results from the present study confirm that the last piglet in the litter has an unusually prolonged birth interval (Randall, 1972; van Rens and van der Lende, 2004) and a consequent increased risk of stillbirth. The reason for this is not immediately apparent. One possibility is that the last birth interval was prolonged due to exhaustion of the sow; however, there was no significant relationship between the accumulated time to reach the birth of the last piglet and the duration of the last birth interval. Sow exhaustion as an explanation is also not consistent with the fact that only the last piglet was affected. If sow exhaustion were the explanation, birth intervals should increase steadily with proportion of the litter farrowed. Alternatively, if the prolonged last birth interval was due to some aspect of the piglet being located at the ovarian end of the uterine horn, one might expect that the last two piglets (one for each uterine horn) would have prolonged birth intervals.

The birth process occurs in two stages. In the first stage, uterine contractions drive the piglet into the cervi- 
cal opening. Entry of the piglet into the cervix stimulates a "pushing" reflex, and birth is completed by contraction of the abdominal muscles to expel the piglet. The delay in the last birth position could be due to delays in either stage. Very little is known about the control of uterine contractions during farrowing in pigs. The farrowing process is initiated by fetal glucocorticoids (First and Staigmiller, 1973; First and Bosc, 1979), similar to sheep and humans (Whittle et al., 2001). Also similar to sheep, the onset of farrowing is associated with increased placental estrogen production and increased release of prostaglandins (Guthrie, 1985; Watts et al., 1988). Oxytocin is released during farrowing (Gilbert et al., 1994; LundinSchiller et al., 1996) and exogenous oxytocin stimulates uterine contractions and can hasten farrowing (Mota-Rojas et al., 2005a,b). Relaxin is also released from the corpora lutea just before farrowing; this suppresses uterine contractions (Watts et al., 1988) and stimulates changes in the uterus and cervix in preparation for farrowing (EldridgeWhite et al., 1989; O'Day et al., 1989; O'Day-Bowman et al., 1991). Curiously, plasma relaxin concentrations are positively associated with birth intervals (Wathes et al., 1989), perhaps due to the inhibitory effect of relaxin on uterine contractions. Administration of anti-porcine relaxin, however, also delays delivery of piglets (Cho et al., 1998). Of these factors, only estrogen and prostaglandin originate from fetuses/placentas and therefore might be affected by piglets remaining in the uterus during farrowing. Results from the present study indicate no association between plasma estradiol and birth intervals and therefore do not support a role for loss of placental estrogen as a mechanism for the prolonged last birth interval. Large amounts of prostaglandin $F_{2 \alpha}$ are released from the uterus during and after parturition (Gooneratne et al., 1983; Watts et al., 1988; Lundin-Schiller et al., 1996). Both the endometrium and placenta are likely to be sources of prostaglandin. In sheep, endometrium releases primarily prostaglandin $F_{2 \alpha}$, while the placenta secretes primarily prostaglandin $E_{2}$ (Whittle et al., 2001). Prostaglandin $\mathrm{F}_{2 \alpha}$ potentiates uterine contractility. It seems possible that placental prostaglandin production (either $\mathrm{PGF}_{2 \alpha}$ or $\mathrm{E}_{2}$ ) may be necessary to maintain the farrowing process, and that prostaglandin release from only a single remaining live placenta within the uterus may not be able to sustain efficient uterine contractions. Alternatively, a single remaining piglet in the uterus may be unable to efficiently trigger the "pushing" reflex to stimulate completion of delivery. An understanding of the mechanisms of prolonged birth in this position could lead to reduced incidence of stillbirth.

\section{Acknowledgments}

Authors wish to acknowledge the technical help of S. Paus, S. Hassler, M. Judy, D. Sypherd, A. Kruger, J. Holman, D. Loudon and W. Peshek during these experiments and L. Parnell for preparation of this manuscript.

\section{References}

Canario, L., Roy, N., Gruand, J., Bidanel, J.P., 2006. Genetic variation of farrowing kinetics traits and their relationships with litter size and perinatal mortality in French Large White sows. J. Anim. Sci. 84, 1053-1058.

Cassady, J.P., Johnson, R.K., Pomp, D., Rohrer, G.A., Van Vleck, L.D., Spiegel, E.K., Gilson, K.M., 2001. Identification of quantitative trait loci affecting reproduction in pigs. J. Anim. Sci. 79, 623-633.

Cho, S.-J., Dlamini, B.J., Klindt, J., Schwabe, C., Jacobson, C.D., Anderson, L.L., 1998. Antiporcine relaxin (antipRLX540) treatment decreases relaxin plasma concentration and disrupts delivery in late pregnant pigs. Anim. Reprod. Sci. 52, 303-316.

Christenson, R.K., Ford, J.J., Redmer, D.A., 1985. Metabolic clearance and production rates of oestradiol and progesterone during pubertal and postpubertal development in gilts. J. Reprod. Fertil. 75, 247-253.

Dandliker, W.B., Brawn, R.J., Hsu, M.L., Brawn, P.N., Levin, J., Meyers, C.Y., Kolb, V.M., 1978. Investigation of hormone-receptor interactions by means of fluorescence labeling. Cancer Res. 38, 4212-4224.

Dwyer, R.J., Robertson, H.A., 1980. Oestrogen sulphatase and sulphotransferase activities in the endometrium of the sow and ewe during pregnancy. J. Reprod. Fertil. 60, 187-191.

Dziuk, P., 1975. Parturition in the pig. Illinois Res. 17, 18-19 (University of Illinois Agricultural Experiment Station).

Dziuk, P.J., Harmon, B.G., 1969. Succession of fetuses at parturition in the pig. Am. J. Vet. Res. 30, 419-421.

Edgerton, L.A., Erb, R.E., Harrington, R.B., 1971. Metabolites of progesterone and estrogen in domestic sow urine. III. Effect of litter size. J. Anim. Sci. 32, 936-942.

Eldridge-White, R., Easter, R.A., Heaton, D.M., O'Day, M.B., Petersen, G.C., Shanks, R.D., Tarbell, M.K., Sherwood, O.D., 1989. Hormonal control of the cervix in pregnant gilts. I. Changes in the physical properties of the cervix correlate temporally with elevated serum levels of estrogen and relaxin. Endocrinology 125, 2996-3003.

Fahmy, M.H., Bernard, C., 1971. Causes of mortality in Yorkshire pigs from birth to 20 weeks of age. Can. J. Anim. Sci. 51, 351-359.

Fahmy, M.H., Holtmann, W.B., MacIntyre, T.M., Moxley, J.E., 1978. Evaluation of piglet mortality in 28 two-breed crosses among eight breeds of pig. Anim. Prod. 26, 277-285.

First, N.L., Bosc, M.J., 1979. Proposed mechanisms controlling parturition and the induction of parturition in swine. J. Anim. Sci. 48, 1407-1421.

First, N.L., Staigmiller, R.B., 1973. Effects of ovariectomy, dexamethasone and progesterone on the maintenance of pregnancy in swine. J. Anim. Sci. 37, 1191-1194.

Gilbert, C.L., Goode, J.A., McGrath, T.J., 1994. Pulsatile secretion of oxytocin during parturition in the pig: temporal relationship with fetal expulsion. J. Physiol. 475, 129-137.

Gooneratne, A.D., Bryant-Greenwood, G., Walker, F.M., Nottage, H.M., Hartmann, P.E., 1983. Pre-partum changes in the plasma concentrations of progesterone, relaxin, prostaglandin F-2 alpha and 13,14-dihydro-15-keto prostaglandin F-2 alpha in meclofenamic acid-treated sows. J. Reprod. Fertil. 68, 33-40.

Guthrie, H.D., 1985. Control of time of parturition in pigs. J. Reprod. Fertil. Suppl. 33, 229-244.

Kensinger, R.S., Collier, R.J., Bazer, F.W., Kraeling, R.R., 1986. Effect of number of conceptuses on maternal hormone concentrations in the pig. J. Anim. Sci. 62, 1666-1674.

Lubahn, D.B., McCarty Jr., K.S., McCarty Sr., K.S., 1985. Electrophoretic characterization of purified bovine, porcine, murine, rat, and human uterine estrogen receptors. J. Biol. Chem. 260, 2515-2526.

Lundin-Schiller, S., Kreider, D.L., Rorie, R.W., Hardesty, D., Mitchell, M.D., Koike, T.I., 1996. Characterization of porcine endometrial, myometrial, and mammary oxytocin binding sites during gestation and labor. Biol. Reprod. 55, 575-581.

Mesa, H., Safranski, T.J., Cammack, K.M., Weaber, R.L., Lamberson, W.R., 2006. Genetic and phenotypic relationships of farrowing and weaning survival to birth and placental weights in pigs. J. Anim. Sci. 84, 32-40.

Mota-Rojas, D., Martínez-Burnes, J., Trujillo, Ma.E., López, A., Rosales, A.M., Ramírez, R., Orozco, H., Merino, A., Alonso-Spilsbury, M., 2005a. Uterine and fetal asphyxia monitoring in parturient sows treated with oxytocin. Anim. Reprod. Sci. 86, 131-141.

Mota-Rojas, D., Nava-Ocampo, A.A., Trujillo, M.E., Velázquez-Armenta, Y., Ramírez-Necoechea, R., Martínez-Burnes, J., Alonso-Spilsbury, M., 2005b. Dose minimization study of oxytocin in early labor in sows: uterine activity and fetal outcome. Reprod. Toxicol. 20, 255259.

O’Day, M.B., Winn, R.J., Easter, R.A., Dziuk, P.J., Sherwood, O.D., 1989. Hormonal control of the cervix in pregnant gilts. II. Relaxin promotes changes in the physical properties of the cervix in ovariectomized hormone-treated pregnant gilts. Endocrinology 125, 3004-3010.

O’Day-Bowman, M.B., Winn, R.J., Dziuk, P.J., Lindley, E.R., Sherwood, O.D., 1991. Hormonal control of the cervix in pregnant gilts. III. Relaxin's influence on cervical biochemical properties in ovariectomized 
hormone-treated pregnant gilts. Endocrinology 129, 1967-1976.

Oliviero, C., Heinonen, M., Valros, A., Hälli, O., Peltoniemi, O.A.T., 2008. Effect of the environment on the physiology of the sow during late pregnancy, farrowing and early lactation. Anim. Reprod. Sci. 105, 365-377.

Randall, G.C.B., 1972. Observations on parturition in the sow. I. Factors associated with the delivery of the piglets and their subsequent behaviour. Vet. Rec. 90, 178-182.

Redmer, D.A., Day, B.N., 1981. Ovarian activity and hormonal patterns in gilts fed allyl trenbolone. J. Anim. Sci. 53, 1088-1094.

Robertson, H.A., Dwyer, R.J., King, G.J., 1985. Oestrogens in fetal and maternal fluids throughout pregnancy in the pig and comparisons with the ewe and cow. J. Endocrinol. 106, 355-360.

Sprecher, D.J., Leman, A.D., Dziuk, P.D., Cropper, M., DeDecker, M., 1974. Causes and control of swine stillbirths. J. Am. Vet. Med. Assoc. 165, 698-701.

van Dijk, A.J., van Rens, B.T.T.M., van der Lende, T., Taverne, M.A.M., 2005. Factors affecting duration of the expulsive stage of parturition and piglet birth intervals in sows with uncomplicated, spontaneous farrowings. Theriogenology 64, 1573-1590.

van Rens, B.T.T.M., van der Lende, T., 2004. Parturition in gilts: duration of farrowing, birth intervals and placenta expulsion in relation to maternal, piglet and placental traits. Theriogenology 62, 331-352.

Wathes, D.C., King, G.J., Porter, D.G., Wathes, C.M., 1989. Relationship between pre-partum relaxin concentrations and farrowing intervals in the pig. J. Reprod. Fertil. 87, 383-390.

Watts, A.D., Flint, A.P.F., Foxcroft, G.R., Porter, D.G., 1988. Plasma steroid, relaxin and dihydro-keto-prostaglandin F-2 $\alpha$ changes in the minipig in relation to myometrial electrical and mechanical activity in the prepartum period. J. Reprod. Fertil. 83, 553-564.

Whittle, W.L., Patel, F.A., Alfaidy, N., Holloway, A.C., Fraser, M., Gyomorey, S., Lye, S.J., Gibb, W., Challis, J.R.G., 2001. Glucocorticoid regulation of human and ovine parturition: The relationship between fetal hypothalamic-pituitary-adrenal axis activation and intrauterine prostaglandin production. Biol. Reprod. 64, 1019-1032. 